\title{
Acessibilidade para pessoas com deficiência visual no Moodle
}

Cristina Madeira Coelho

Patricia Neves Raposo

Eduardo Xavier da Silva

Ana Carolina Freitas de Almeida

Universidade de Brasília

\section{Resumo}

Uma experiência de trabalho pedagógico é utilizada para descrição da construção de acessibilidade em Ambiente Virtual de Aprendizagem-AVA para pessoas com deficiência visual. Três aspectos são priorizados: descrição textual das imagens e tabelas; organização das informações; configuração específica do editor de textos do MOODLE para utilização de softwares leitores de tela. Concluímos indicando que o valor da experiência educacional, tanto em seu aspecto inclusivo quanto no uso de tecnologias na educação, está nos desafios que nos permitiram fazer avançar nossa compreensão sobre a relação sujeito/ensino-aprendizagem/conhecimento em novas formas de vivências educacionais.

Palavras-chave: Subjetividade. Acessibilidade. Inclusão. 


\section{Accessibility for the visually impaired in Moodle}

An educational work experience is used to describe how a Virtual Learning Environment, the Moodle, was made accessible for the visually impaired. Three aspects are emphasized: textual description of images and tables; organization of the information, and the specific configuration of Moodle's text editor for the use of screen reading software. We conclude by pointing out that the main value of the educational process, in both its aspects of inclusion and technology use, is in the challenges that allowed us to advance in our understanding of the relationship among subjects/teaching and learning/knowledge in new types of educational experiences.

Keywords: Subjectivity. Accessibility. Inclusion.

\section{Accesibilidad en el moodle para sujetos con discapacidad visual}

Una experiencia de trabajo pedagógico es utilizada para describir la construcción de la accesibilidad en un Ambiente Virtual de Aprendizaje - AVA para una maestra con discapacidad visual. Tres aspectos son abordados: al la descripción textual de las imágenes y tablas; b) la organización de las informaciones; c) la configuración específica del editor de textos del MOODLE para la utilización del software leedor de pantallas. Se concluye indicando que el valor de la experiencia educacional, tanto en su aspecto inclusivo como en el uso de las nuevas tecnologías en la educación, está en los desafíos que nos han traído y que nos permiten avanzar nuestra comprensión sobre la relación sujeto/enseñanza-aprendizaje/conocimiento, en nuevas formas de vivencias educacionales.

Palabras clave: Subjetividad. Accesibilidad. Inclusión. 


\section{Introdução}

Depois de estabelecida a institucionalização dos processos educacionais, por volta do final do século XVII, poucas foram as mudanças que os espaços e as formas da ação pedagógica escolares sofreram. Passamos pela Revolução Industrial, a qual modificou profundamente a organização social, com novas formas de produção e consumo de bens. Ainda que não vislumbremos possibilidades efetivas da paz, passamos por muitas guerras regionais e duas grandes guerras mundiais. Passamos pela revisão da experiência colonialista com a libertação das colônias e a instauração de novas geopolíticas mundiais. Temos passado por diferentes regimes políticos: impérios, ditaduras, regimes democráticos de direita e de esquerda, e a alternância entre eles. Passamos pela pílula que libertou as mulheres heterossexuais e sua sexualidade, e permitiu o controle da natalidade. Vamos passando pelo impacto do advento de novas epidemias globais, a AIDS, a gripe aviária, a gripe A (H1N1). Enfim, processos e movimentos históricos que, além de modificarem fortemente costumes, tradições, relações humanas e subjetividades, permitiram que questionássemos a instituição escolar. Foram, porém, insuficientes para transformar, em sua essência, a tradição escolar na qual matriculamos nossa infância.

A primeira década do século XXI vai ser historicamente caracterizada pela cultura midiática globalizada decorrente do uso intensivo de novas tecnologias de informação e comunicação, as TICs. Assim, nesse início de século pudemos vivenciar uma nova transformação cultural: a globalização, anunciada por MacLuhan (1911-1980), que ocorreu nas últimas décadas do século XX por meio das grandes mídias do jornalismo, rádio e televisão para uma sociedade conectada em rede em que os contextos sociais passam a ser vivenciados também por meio das tecnologias de comunicação pessoal produzindo mudanças nos relacionamentos sociais, pessoais, profissionais etc., bem como novas formas de produção intelectual.

Na sociedade em rede, espaços-tempos antes separados agora se interpenetram e passam a privilegiar uma cultura do conhecimento e, portanto, da aprendizagem. Essa convergência exige novas formas da compreensão de processo educacional. Nota-se a substituição de um modelo de ensino tecnicista, em que se preparavam indivíduos para o desempenho de papéis, por uma prática pedagógica em que a apropriação dos conhecimentos se dá a partir de aprendizagens significativas, com o oferecimento de informações relevantes que possam ser relacionadas a conceitos existentes ou preexistentes na estrutura cognitivo-afetiva dos sujeitos, as quais acabam gerando novas aprendizagens e novos desenvolvimentos.

Como instituição social por excelência, a escola não ficou de fora desse processo de transformação histórico-cultural que atingiu fortemente a sociedade humana. No 
Brasil, e especificamente na Educação Superior, essa transformação pode ser caracterizada pela busca de novas formas de implementar e/ou ampliar programas de Educação a Distância, EaD. Mesmo antes do advento das TICs, a desterritorialização do processo de ensino proposto pela EaD procurou, no Brasil, resgatar dívida educacional histórica que exclui grande parcela da população do acesso a Educação Superior. Até hoje, a quantidade continua sendo o parâmetro máximo para a avaliação de programas e, portanto, o atendimento de grandes contingentes humanos um objetivo perseguido.

Dessa forma, nesse período em que vivemos a transição de um milênio, temos sido testemunhas e agentes de fortes movimentos que desafiam a tradição educacional de nossa sociedade. Será que tais movimentos serão suficientes para que, como agentes sociais, possamos organizar formatos educacionais decorrentes de uma pedagogia criativa e criadora? Ou será que tais desafios serão meramente engolidos pela tradição que conseguiu ultrapassar tantos e tão profundos processos históricos?

Nesse artigo, refletimos sobre uma experiência de trabalho pedagógico em contexto regular de Educação Superior em que se relacionam dois entre esses movimentos educacionais atuais, a saber, a inclusão de pessoas com deficiências e o uso de novas tecnologias na educação. A descrição da experiência pedagógica procura construir argumentação que indica que, em si, tanto as políticas inclusivas quanto o uso das tecnologias não são suficientes para a transformação das concepções que presidem o modelo escolar tradicional.

Assim, o avanço do movimento de inclusão de pessoas com deficiência nos contextos educacionais passou a exigir ações relacionadas ao atendimento às diversidades dos processos de aprendizagem, em um desafio constante às formas tradicionais de organização do trabalho pedagógico. Novas formas da ação pedagógica, orientadas para a diversidade dos processos do aprender, são necessárias para que possamos falar de inclusão, do contrário, continuaremos repetindo situações em que o sucesso da experiência educacional decorria somente da adaptação dos sujeitos ao processo, como no modelo educacional da integração (Carvalho, 2004).

Muito embora a inclusão seja reconhecida e considerada como um valor, a compreensão da inclusão educacional como uma bandeira de luta ou um bem em si mesmo é redutora (Tunes; Bartholo, 2006). A instituição de práticas educacionais de não-exclusão decorre da compreensão de que as práticas pedagógicas são impactadas pelas concepções que temos sobre a deficiência, sobre o sujeito que aprende e sobre as diferentes formas de compreender a relação entre aprendizagem e desenvolvimento.

Por outro lado, o movimento do avanço tecnológico nos uniu em uma rede virtual planetária. Surfar a terceira onda é participar de um grande fórum inclusivo e, para muitos de nós, deixar de ser uma ilha. Vivências cotidianas de participação em uma 
rede social planetária, que passa a ser "natural" para a geração dos nativos digitais ${ }^{1}$ e permite aos sujeitos o acesso imediato a informações, apresentam enorme potencial de impactar processos de construção de conhecimento. Assim, nesse ambiente, as possibilidades virtuais de aprendizagem implodem os espaços confinados que caracterizaram a organização escolar desde os seus primórdios, mas cada vez mais demandam que se compreenda a aprendizagem como não dissociada do desenvolvimento humano.

Ambos, a inclusão de pessoas com deficiências e as novas tecnologias desenvolvidas para a educação, se alinham como desafios complexos, pois, de forma ambígua, apesar de carregarem o potencial para a mudança, podem ser vivenciados de forma extremamente tradicional em que se mantém a representação descritivo-reprodutiva sobre a aprendizagem. Dessa forma, se constituem como movimentos sociais com forte potencial de impacto nas configurações da subjetividade social e individual (González Rey, 2003) dos sujeitos envolvidos nas práticas do cotidiano educacional, e, assim, o impacto dos mesmos não pode ser compreendido de forma redutora ou fragmentada. Nessa compreensão que dá sustentação teórica a nossa vivência educacional, a aprendizagem,

como forma complexa de aprendizagem especificamente humana, é concebida como um processo de subjetividade [...] em que se articulam diferentes dimensões cognitivointelectual, afetivo-relacional, personológica, etc., implicando formações dinâmicas mais complexas e integradoras que constituem configurações de sentidos subjetivos e que qualificam o processo do aprender. (Mitjáns Martínez, 2006, p. 373).

0 presente artigo apresenta nossa experiência com a disciplina Educando com Necessidades Educacionais Especiais - ENEE. Nela, nossa experiência educacional utilizou-se de estratégias que relacionaram processos de inclusão e tecnologia, compreendidos como processos de sentido e de significação que articulam, simultaneamente, para os sujeitos envolvidos na experiência, planos sociais, culturais, relacionais, linguísticos e emocionais, quer dizer, processos simultaneamente sociais e individuais. Assim, durante o processo de preparação da disciplina, para além de desenvolver uma técnica ou organizar uma metodologia, foi sendo construído um processo de aprendizagem inclusivo em uma rede social e tecnológica que foi se organizando pela motivação dos participantes individualmente e em grupo. E culminou com a vivência da disciplina que atualmente já está em sua terceira edição.

Como princípios gerais conformadores da experiência, assumimos uma leitura específica dos princípios liberais "Liberdade, Igualdade e Fraternidade”, ou seja, que

1. Nativos Digitais são todos aqueles que nasceram com a tecnologia e são fluentes na linguagem digital dos computadores; já Imigrantes Digitais são todos aqueles que falam a linguagem digital, mas que revelam dificuldades em compreender e expressar-se digitalmente. Disponível em: <http://www.nativosdigitais.com>. Acesso em: 12 out. 2009. 
1) o princípio da liberdade não se confunda com o individualismo extremado e a qualquer custo; 2) o princípio da igualdade não apague as singularidades dos processos humanos do aprender e 3) o princípio da fraternidade se estabeleça como uma ética baseada na convivência e que, portanto, dê forma a ações orientadas pelo e para o outro.

\section{Os relatos da experiência}

\section{A professora}

Este texto toma por base a construção de uma metodologia de trabalho na elaboração de cursos em ambientes de aprendizagem utilizados na Educação à Distância (EaD), com a utilização de recursos de acessibilidade para pessoas com deficiências, especialmente deficiência visual. Como já mencionado, nossa proposta partiu de uma experiência realizada em 2008, com a elaboração da disciplina ENEE do curso de Pedagogia à Distância da Universidade de Brasília (UnB), participante do programa da Universidade Aberta do Brasil - UAB. Esta disciplina já era e continua sendo ministrada no curso de Pedagogia na modalidade presencial e uma das professoras é pessoa cega.

A proposição de elaborar uma disciplina na modalidade à distância traduziu-se em duplo desafio motivador: se por um lado pretendeu-se criar recursos de acessibilidade para a professora cega e, daí, para um grupo que talvez esteja excluído da modalidade da $\mathrm{EaD}$, por outro se considerava o planejamento pedagógico que permitiria (e permitiu) a um grupo de futuros pedagogos e pedagogas compreenderem e vivenciarem na prática conceitos como acessibilidade e tecnologias assistivas².

Por já ser professora da disciplina há alguns anos e, portanto, ter a experiência de ministrá-la, compreendíamos que a professora, além de acompanhar todos os processos e estudantes que participam da rede constituída para a modalidade proposta, deveria ser a autora da disciplina, planejando textos, escolhendo atividades e material ilustrativo, enfim, dominando o planejamento do Ambiente Virtual de Aprendizagem AVA como um todo.

Inicialmente, buscamos ampliar a discussão contatando grupos de discussão sobre acessibilidade na web e sobre ambientes de aprendizagem; convidamos professores e

2. Tecnologia assistiva é o "ramo da ciência voltado para a pesquisa, desenvolvimento e aplicação de instrumentos que aumentam ou restauram a função humana [...]. Tecnologia Assistiva é, portanto, toda aquela desenvolvida para permitir 0 aumento da autonomia e independência de idosos, de pessoas com deficiência ou de pessoas com mobilidade reduzida em suas atividades domésticas ou ocupacionais de vida diária." Disponível em: <http://www.mct.gov.br/index.php/ content/view/18622.html>. Acesso em 11 jul. 2007. 
professoras com estudos e interesses na educação utilizando o ambiente Moodle e contamos com pessoas determinadas para o êxito do processo. 0 grupo efetivo de trabalho foi constituído pelas autoras e autor desse texto. Inicialmente éramos duas professoras da área da Educação Especial/Inclusiva. 0 fato de a professora regente da disciplina não possuir qualquer conhecimento do Ambiente Virtual de Aprendizagem e este não oferecer suficiente acessibilidade demandou a solicitação de uma tutora especial ${ }^{3}$ com conhecimento do conteúdo a ser ministrado. Essencial para o sucesso e desenvolvimento do trabalho foi o envolvimento próximo de um profissional motivado para as questões da acessibilidade no Moodle que possuía (e agora possui mais ainda) conhecimento técnico em Ambientes Virtuais de Aprendizagem lo depoimento do mesmo sobre a experiência vem a seguir).

A disciplina Educando com necessidades educacionais especiais pretende inserir o futuro pedagogo e pedagoga no universo da educação inclusiva. A partir de crenças e vivências do senso comum, as atividades propostas - leituras, exercícios e práticas se organizam em estratégias para que os/as estudantes possam refletir sobre a diversidade humana e as formas como o paradigma da inclusão foi sendo instituído na experiência histórica, legal e política dos contextos educacionais. Os objetivos da disciplina são:

Geral: Compreender e contextualizar a educação especial e suas implicações na construção do paradigma da inclusão na sociedade atual;

Específicos:

Compreender a significação da educação inclusiva e suas implicações na formação do/a professor/a e no seu trabalho pedagógico/educacional;

Estudar sobre a diversidade de sujeitos e as necessidades educacionais especiais com vistas à compreensão de suas manifestações no desenvolvimento de habilidades e competências no processo de ensino e de aprendizagem;

Identificar a acessibilidade de recursos da Tecnologia da Informação e Comunicação (TIC) como estratégia do processo de ensino aprendizagem de pessoas com necessidades especiais.

Em relação a esse último item, o ambiente Moodle nos ofereceu espaço para demonstrar mediadores técnicos e tecnológicos, como dicionários de LIBRAS (Língua Brasileira de Sinais), programas leitores de tela, vídeos com audiodescrição, janela de LIBRAS, entre outras. Todas, alternativas desconhecidas para a maioria de professores e professoras em formação, e que garantem diferentes formas de acessibilidade.

3. A denominação tutoria especial foi emprestada pelo Programa de Tutoria Especial da UnB que institui colegas apoiadores como pares de alunos com necessidades especiais para o desenvolvimento de atividades acadêmicas dentro e fora da sala de aula. 
A compreensão do conceito de acessibilidade engloba diferentes expansões do significado do termo. Assim, falamos de acessibilidade arquitetônica, urbanística, de mobiliário, de transporte, de informação e comunicação. Ferramenta fundamental de apoio ao desenvolvimento de práticas pedagógicas de professores e professoras envolvidos/as com turmas inclusivas representa fator essencial para garantia de práticas cidadãs para milhões de pessoas com deficiência. A inclusão da acessibilidade como conteúdo transdiciplinar dá ao professor/a em formação a perspectiva de uma prática pedagógica que se utiliza de tecnologias plurais e que podem responder a diversas necessidades e exigências de aprendizagem.

A expressão "acessibilidade" representa não apenas o direito ao acesso à rede de informações,

mas também o direito de eliminação de barreiras arquitetônicas, de disponibilidade de comunicação, de acesso físico, de equipamentos e programas adequados, de conteúdo e apresentação da informação em formatos alternativos (Disponível em: <http://www. acessobrasil.org.br/index.php?itemid=45>. Acesso em: 20 set. 2009).

O sítio citado indica situações e características que criadores/as de conteúdo na web devem observar durante a concepção de uma página, e apresenta situações potencialmente caracterizadoras do usuário/a, as quais procuram padronizar potenciais dificuldades para o acesso à informação tecnológica:

1. Incapacidade de ver, ouvir ou deslocar-se, ou grande dificuldade - quando não a impossibilidade - de interpretar certos tipos de informação.

2. Dificuldade visual para ler ou compreender textos.

3. Incapacidade para usar o teclado ou o mouse, ou não dispor deles.

4. Insuficiência de quadros, apresentando apenas texto ou dimensões reduzidas, ou uma ligação muito lenta à Internet.

5. Dificuldade para falar ou compreender, fluentemente, a língua em que o documento foi escrito.

6. Ocupação dos olhos, ouvidos ou mãos, por exemplo, ao volante a caminho do emprego, ou no trabalho em ambiente barulhento.

7. Desatualização, pelo uso de navegador com versão muito antiga, ou navegador completamente diferente dos habituais, ou por voz ou sistema operacional menos difundido.

Embora tivéssemos informações sobre alguns recursos de acessibilidade no moodle, a versão com que iniciamos a elaboração da disciplina não alcançava nossas necessidades, e a acessibilidade desejada foi sendo conquistada com experiências e tentativas do grupo. 
Questões simples e comuns, tais como redigir e responder um fórum, ver relatórios de atividades, avaliar uma atividade e até ler um texto em formato adequado, foram organizadas de forma viável ou criativa para gerar acessibilidade. Textos foram incluídos, e houve uma organização hierárquica dos links de acordo com o uso e a importância para permitir a navegabilidade e usabilidade por pessoas com deficiência visual.

Em relação à escolha de imagens que fizeram parte das atividades pedagógicas, utilizou-se estratégia semelhante a um outro recurso da tecnologia assistiva e que favorece a inclusão de pessoas com deficiência visual a um mundo de meios visuais e auditivos: a audiodescrição4.

A alternativa utilizada, denominada por nós de textodescrição, se constituiu na descrição das imagens presentes, na informação dos detalhes e na explicitação de sua importância no contexto dos conteúdos e temas. A descrição de fotos, imagens e vídeos é significativa para a aprendizagem de estudantes com deficiência visual à medida que proporciona informações relevantes à construção do conhecimento.

De acordo com Ruiz-Velazco (2003), apresentar conteúdos em determinados formatos só vai adquirir significado e sentido a partir das vivências das pessoas que acessam esses conteúdos. E, portanto, esse é um processo que depende, entre outros, de antecedentes socioculturais das pessoas. Assim, a contextualização vai possibilitar 0 valor do uso que o conteúdo possa ter para o seu destinatário.

Desta forma, os textos descritos devem pertencer ao contexto de oralidade e ao universo cultural das pessoas. A linguagem, elemento-chave para o desenvolvimento da leitura, é essencial para o desenvolvimento das funções de comunicação e generalização de conceitos. Uma pessoa cega, e também pessoas ledoras videntes, lerão e compreenderão textos com maior facilidade se conhecerem o significado das palavras escritas, pois

Um equivalente ou correspondente textual deve comunicar, com clareza e objetividade, todas as informações apresentadas no conteúdo não-textual. Por essa razão, é fundamental analisar os objetivos das figuras em relação ao texto visto que as imagens ilustram, enfocam informações, apresentam uma carga afetiva e têm grande dimensão simbólica. Elaborar um correspondente textual representa uma oportunidade de flexibilizar o modo de apresentação da informação com vistas a atender a necessidades específicas ou, ainda, a representar uma opção do receptor da informação (Raposo; Mól; Pires, 2011, p. 139).

4. "O recurso consiste na tradução de imagens em palavras. É, portanto, também definido como um modo de tradução audiovisual intersemiótico, em que o signo visual é transposto para o signo verbal. Essa transposição caracteriza-se pela descrição objetiva de imagens que, paralelamente e em conjunto com as falas originais, permite a compreensão integral da narrativa audiovisual. Como o próprio nome diz, um conteúdo audiovisual é formado pelo som e pela imagem, que se completam. A audiodescrição vem então preencher uma lacuna para o público deficiente visual." Disponível em: <http://blig.ig.com.br/acessivelparatodos/2009/01/13/audiodescricao-tecnologia-assistiva-que-traduz-imagens-empalavras>. Acesso em 20 set. 2009. 
Antes de a disciplina ir para o "ar" testamos cada uma das alternativas de acessibilidade encontrada para verificar sua efetividade no processo. Um outro aspecto considerado importante foi o nível de conhecimento tecnológico do usuário com deficiência. Usuários podem dominar a tecnologia e se utilizar dos recursos de acessibilidade com grande eficácia. Outros, porém, têm usabilidade e navegabilidade medianas ou abaixo da média. Embora nossa professora esteja entre o primeiro grupo, procuramos considerar estes últimos como referências para ampliar a acessibilidade para grande parte das pessoas com deficiência.

\section{0 profissional do desenvolvimento web}

Hoje vivemos a era das novas tecnologias de informação, que vêm crescendo e se tornando importante fonte de notícia, comércio, serviços, lazer e educação, além de proporcionar novas formas de interação através de suas ferramentas de comunicação. Com a internet ampliam-se, também, as possibilidades de educação inclusiva, não somente pelo acesso ao saber e à informação, mas, principalmente, porque o recurso potencializa a criação de alternativas metodológicas para práticas pedagógicas, abrindo-se espaços de oportunidades para as pessoas cujos padrões de aprendizagem não seguem os quadros típicos de desenvolvimento.

Desta forma, a internet vem se consubstanciando como um ambiente de comunicação, de relacionamento e de aprendizagem potencial para as diversidades. A idéia principal é que ela não seja uma rede de computadores, mas de pessoas interconectadas. Pessoas dos mais diferentes lugares, das mais diversas profissões e necessidades, que se comunicam não por estarem próximas, mas por partilharem interesses e ideias. Pessoas que buscam informação, mas que também têm conhecimentos e os socializam, colaboram entre si, compartilham propostas, recursos e aprendem juntas (Lévy, 2001).

Assim como o sistema Braille pode ser considerado uma evolução na educação de pessoas com deficiência visual, os softwares de leitura de tela constituem a evolução que garante o acesso dessas pessoas à informação. A EaD traz o potencial de ser um novo avanço, por possibilitar novo espaço de conexão e interação entre estudantes e professores/as. Mas isto somente será possível se os processos de ensino-aprendizagem forem compreendidos como atividades relacionais e se os Ambientes Virtuais de Aprendizagem forem adequadamente adaptados às necessidades, tanto individuais quanto relacionais.

Visando garantir o acesso às diversas mídias e ambientes virtuais, partimos do princípio de que todos - alunos/as e professores/as -, independente da sua necessidade, 
deveriam ter acesso às informações contidas nesses contextos. Assim, o desenvolvimento do material didático realizado obedeceu todas as convenções de programação que atendam às necessidades de acessibilidade para todos.

Alguns desses requisitos que observamos foram: al 0 acesso ao sistema não pode significar uma barreira para o/a professor/a e para o aluno/a; b) As estratégias de desenvolvimento devem ser adaptadas à forma de navegação dos softwares de leitura de tela, agrupando e organizando as informações de forma que facilitem a localização da informação por parte da pessoa deficiente visual; c) As interfaces do Ambiente Virtual de Aprendizagem devem conter o mínimo de informações estritamente necessárias ao processo de aprendizagem, organizadas de forma planejada e obedecendo a uma hierarquia clara para navegação, não deixando de proporcionar estratégia de localização ao usuário.

Como a disciplina é parte do curso de graduação à distância em Pedagogia na Universidade de Brasília, utiliza-se um sistema de informações de domínio público lopen source), o LMS (Learning Management System) mais utilizado no mundo na atualidade, que é a plataforma virtual Moodle, um sistema de informação dinâmico desenvolvido para hospedar Ambientes Virtuais de Aprendizagem, que são espaços destinados à produção e à oferta de cursos ou disciplinas. 0 Moodle atende minimamente aos requisitos de acessibilidade previstos pelas normas da W3C (World Wide Web Consortiuml em todas as suas versões, e não requer nenhum desenvolvimento de novos componentes para que isto seja possível. É necessário apenas que se adotem algumas boas práticas de desenvolvimento web ao se configurar e criar o ambiente virtual em que se dará o curso.

Quando se fala em boas práticas de desenvolvimento web, isto reflete não no sistema, mas no autor/a do curso e na formação de uma consciência de utilização destas práticas. Nesta experiência partimos de três dificuldades: a descrição textual das imagens, gráficos e tabelas utilizadas no curso; a organização das informações, estabelecendo uma hierarquia e uma sequência lógica para a navegação; a configuração específica do editor de textos do Moodle para utilização de softwares leitores de tela.

Sabemos que uma das grandes dificuldades encontradas pela pessoa com deficiência visual ao navegar pela internet é a interpretação de recursos gráficos, uma vez que os sistemas de leitura de tela acessam apenas os códigos HTML, utilizados para criar páginas de internet. Há, portanto, necessidade de inserir nestes códigos uma descrição textual do recurso gráfico apresentado. Para tal, o Moodle já apresenta esta opção como obrigatória ao se anexar uma imagem ao curso. Porém, normalmente, a prática de apresentar uma descrição completa e contextual do recurso gráfico é negligenciada pela maioria das pessoas que criam cursos. Isso se reflete como dificuldade e, muitas 
vezes, impossibilidade da compreensão da imagem pelos usuários de softwares leitores de tela. Portanto, é de fundamental importância que esta descrição seja considerada pelo autor/a no momento de concepção da ação educacional para garantir, a todos, o pleno entendimento dos recursos gráficos utilizados.

\section{Figura 01: Figura da janela de importação de arquivo de imagem com destaque para o campo de preenchimento obrigatório "Texto alternativo"}

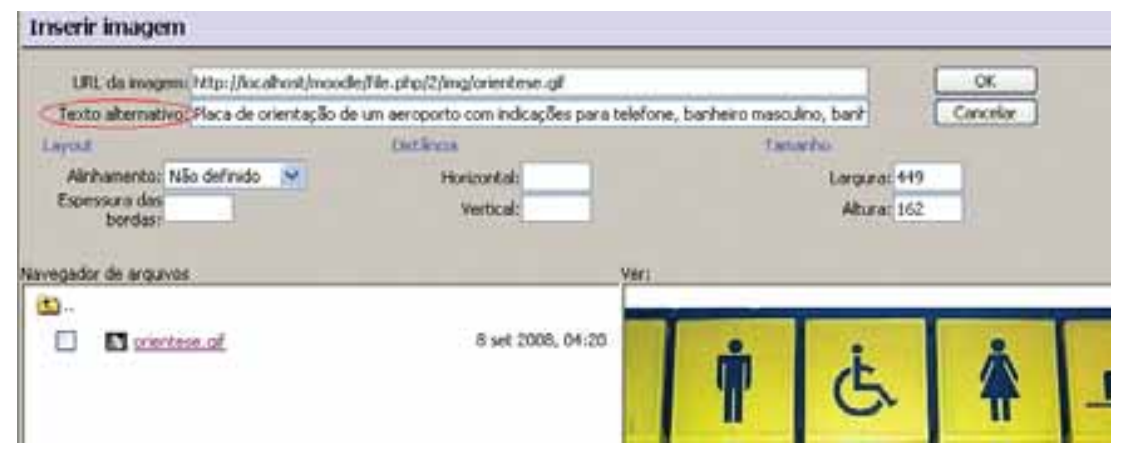

Fonte: AVA da disciplina ENEE (2008)

Outro ponto importante é a organização das informações dentro do ambiente virtual, de forma a garantir uma hierarquia e uma sequência lógica de navegação. 0 tradicional formato de blog ou portfólio, no qual se reúnem em uma mesma tela uma infinidade de informações, com diferentes focos, pode dificultar o entendimento e a localização de informações importantes ao processo de aprendizagem. Quando organizamos estas informações em grupos e criamos uma navegação lógica para que estas informações sejam acessadas, estamos garantindo uma maior autonomia e menor esforço aos usuários de software leitor de tela para encontrar tais informações dentro do AVA.

Nesta experiência optamos por três estratégias para organização do conteúdo: 1) 0 primeiro passo foi organizar as informações dentro do layout do moodle, utilizando as três colunas, seguindo a sequência de grau de importância e necessidade de acesso aos recursos do ponto de vista do usuário. Assim, os links mais utilizados foram localizados no canto superior esquerdo, e os menos utilizados no canto inferior direito; 2) Para permitir que o usuário se localize na página foi utilizado um bloco, que já vem instalado no Moodle e cuja tradução é “links de seção”, permitindo que o usuário navegue por seções, podendo controlar o cursor do software leitor de tela navegando direto para a seção ou semana desejada; 3) A necessidade de localização da informação dentro da página foi considerada como a mais importante para garantir a navegação dentro do ambiente. Dessa forma, o bloco “links de seções” foi localizado como o grupo 
de links que o usuário irá encontrar no canto superior esquerdo, a primeira linha que o ledor de tela encontra e que possibilita ao usuário escolher para onde ir. Os demais blocos foram organizados conforme necessidades específicas do curso.

Figura 02: Figura do layout do Moodle apresentando o bloco “links de seção" localizado no canto superior esquerdo

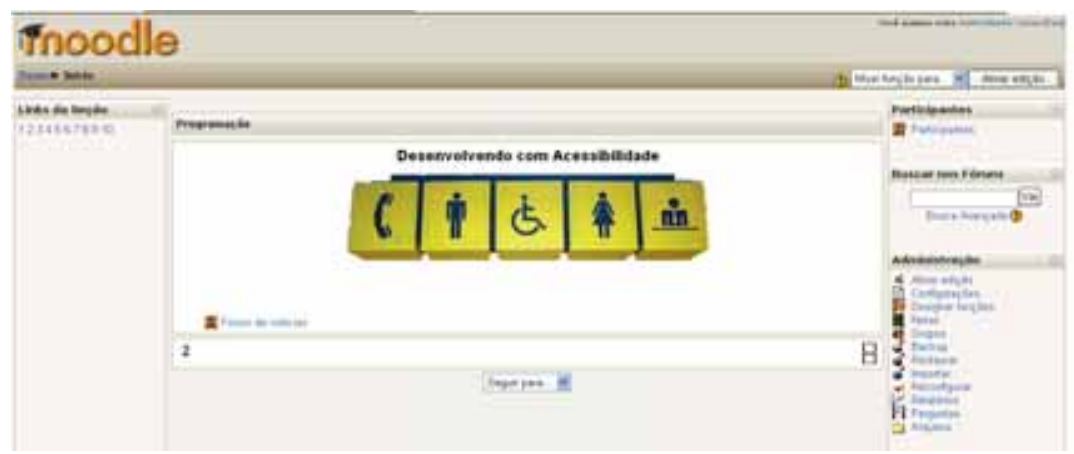

Fonte: AVA da disciplina ENEE (2008)

A última adaptação necessária foi a substituição do editor de HTML, utilizado tanto pelo autor ou autora no momento da construção dos recursos educacionais, quanto pelo aluno ou aluna ao participar da oferta educacional. Este editor permite incorporar recurso da linguagem HTML, como mudar a cor e tamanho da fonte, inserir imagens, criar tabelas, entre outras funcionalidades, mesmo que o usuário não seja um conhecedor desta linguagem. Mas este editor é um impeditivo para a utilização do software leitor de tela, pois ele não apresenta uma navegação acessível.

Assim, houve necessidade de substituir este editor por um outro, também disponível no Moodle, que trabalha o texto sem formatação HTML. Para tal, foi necessário orientar o usuário de leitor de tela a editar o seu perfil e escolher a opção "Ao editar texto: Usar formulário web", o que permitiu a navegação plena em todos os recursos do moodle, inclusive a participação nos fóruns de discussão, sem influenciar a opção dos demais participantes que continuaram a utilizar o editor de HTML padrão.

Figura 03: Figura mostrando o campo do formulário de edição do perfil do usuário indicando a opção "Usar formulários web" ao editar o texto

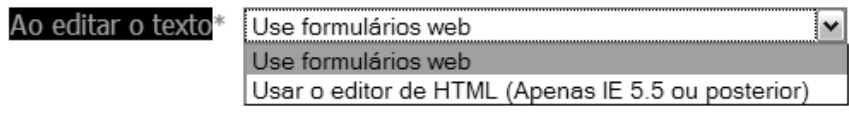

Fonte: AVA da disciplina ENEE (2008) 
Com estas três medidas simples de boas práticas que podem ser adotadas por qualquer autor ou autora de cursos no moodle, foi possível garantir o pleno acesso às informações, respeitando os contextos em que elas estão inseridas e garantindo uma navegação menos trabalhosa por parte dos usuários de softwares leitores de tela.

\section{A tutora especial}

O Ambiente virtual de aprendizagem Moodle se mostrou inicialmente não-acessível a pessoas com deficiência visual que fazem uso de programas de voz para utilizar o computador. Um/a professor/a autor/a de uma disciplina a distância que tenha que acompanhar seu desenvolvimento com tutores/as e alunos/as precisa de pleno acesso aos recursos disponíveis nesse ambiente.

Assim, para garantir que a professora deficiente visual, usuária de programas de voz, pudesse criar e acompanhar a disciplina virtual acessando de forma plena esse ambiente, foram desenvolvidas duas linhas de ação: de um lado, a modificação da estrutura da disciplina, de modo a facilitar a navegação de pessoas que fazem uso de programas de voz através de profissional de desenvolvimento web em contato direto com o grupo efetivo do planejamento da disciplina; de outro, a criação da tutoria especial, que se trata do apoio à professora deficiente visual, usuária de programa de voz, por uma pessoa que tenha conhecimentos básicos tanto de tecnologia de educação quanto sobre a disciplina em questão.

A modificação da estrutura pré-definida do ambiente virtual foi decisiva, pois em testes iniciais não era possível chegar com o programa de voz a vários itens da plataforma moodle, tanto por causa da formação do ambiente em colunas, bem como pela variedade de imagens que não eram enunciadas de maneira clara pelo programa de voz.

Contudo, mesmo com a constante reformulação dessa estrutura, alguns problemas persistiam: dificuldade em criar, editar e formatar novas tarefas, fóruns, glossários, textos, bate-papos.

Essa dificuldade talvez fosse reduzida caso se pensasse em uma disciplina composta de textos colocados pelo/a professor/a e espaços para fichamentos ou resumos de estudantes sobre os textos. Atividades possíveis de serem feitas com o uso de programas de voz de forma independente. Mas a intenção da professora não era reduzir uma ferramenta rica em artifícios que possibilitam a interatividade, a coletividade, a discussão, como é o Moodle, a textos colocados em meio eletrônico. Sua proposta educativa transcendia a prática do que era possível. Essa opção pedagógica embasou a criação da Tutoria Especial. 
A tutora especial inicialmente integrou-se ao grupo com esse amplo objetivo de apoio à professora usuária de programa de voz na criação e acompanhamento da disciplina em meio virtual. Aos poucos, durante a criação da disciplina, as atividades realizadas pela tutora especial foram se tornando mais práticas e exigiam cada vez mais conhecimento sobre o assunto trabalhado na disciplina. Para cada conteúdo, a busca pelos textos escolhidos foi realizada em conjunto, consultando-se livros, sites, reportagens em revistas e jornais. A demanda específica da disciplina exigiu, no entanto, que alguns textos fossem escritos pela professora.

A tutoria auxiliou na escolha e busca de materiais impressos, na digitalização, na formatação, nas referências e na criação dos já referidos textos/descrição. Em sites, a busca acontecia com maior independência pela professora quando estes eram acessíveis ao programa de voz. Em outros casos, sites inacessíveis, documentos com diferentes extensões, hipertextos com links apenas visuais, a opção foi a mesma que norteou a busca de textos impressos, i.e., a pesquisa em conjunto.

De modo a aproveitar as possibilidades oferecidas pelo meio virtual, foram usados na disciplina materiais com linguagens diversificadas, tais como imagens e vídeos. Além das dificuldades na procura por estes materiais, a compreensão dos mesmos é difícil, por sua própria natureza. Descrições e discussões sobre as finalidades dos mesmos foram, portanto, essenciais.

A opção por esses materiais diversificados não surgiu apenas para deixar a disciplina mais 'enfeitada' ou menos 'cansativa'. Considerou-se, no paradigma educacional adotado, a compreensão das diferentes formas de ensino para a diversidade de pessoas potencialmente estudantes do curso de Pedagogia à distância. As imagens, vídeos, músicas e textos diversificados faziam parte do conteúdo da disciplina e tiveram considerável importância na reflexão sobre este conteúdo. As ferramentas disponíveis foram assim exploradas de modo a valorizá-las em suas potencialidades. Talvez não utilizar imagens ou vídeos fosse mais fácil e rápido. No entanto, entendíamos que não seria possível usar uma nova tecnologia de ensino a distância com as mesmas características do ensino presencial. Pois, como afirma Corrêa (2002), mesmo usando recursos tecnológicos avançados, muitas vezes

[...] reproduzimos as mesmas atitudes, o mesmo paradigma educacional pelo qual fomos formados. Não basta trocar de suporte sem trocar nossas práticas educativas, pois estaremos apenas apresentando uma fachada de modernidade, remodelando o "velho" em novos artefatos (Corrêa, 2002, p. 46).

No decorrer da disciplina, a tutoria especial ainda teve seu lugar na avaliação de algumas atividades e modificação através de adaptação/edição de outras. A professora 
fazia questão de acompanhar o trabalho dos tutores e tutoras, as tarefas, glossários e principalmente fóruns e bate-papos. Em atividades como tarefas e fóruns, o ambiente virtual modificado possibilitou o percurso da professora pelo ambiente com bastante independência por meio do programa de voz. Contudo, a atividade de glossário adotada e a postagem de novos tópicos necessitaram do apoio da tutoria especial. De certo modo, o bate-papo talvez tenha sido a ferramenta que, mesmo com o apoio da tutoria, não tenha obtido o sucesso esperado em termos de acessibilidade. Eram muitas falas em curtos espaços de tempo para réplica, o que dificultava a discussão entre tutora e professora. A resposta chegava após novas perguntas já terem sido feitas. 0 sucesso da atividade, no entanto, residiu na potencialização do trabalho coletivo e interacional entre estudantes, tutoras e tutores (de todos os tipos) e professores/as.

A tutoria especial representou a possibilidade de se preparar uma disciplina que se utiliza da tecnologia não apenas como um produto educativo, mas como um novo espaço inter-relacional que reuniu inicialmente os autores desse trabalho no desenho da disciplina e continuou com a acessibilidade da professora e o trabalho de estudantes que, instigados pela vivência efetiva de temas e conceitos tratados na disciplina, tiveram um processo de aprendizagem rico e diferenciado.

\section{Dois anos depois: a fala da professora}

A experiência iniciada em 2008 com a disciplina Educando com Necessidades Educacionais Especiais, ofertada na primeira turma do curso de Pedagogia à distância da UnB e decorrente da experiência do Programa UAB, manteve grandes desafios. $\mathrm{Na}$ continuidade do trabalho, procurou-se responder às seguintes questões: A proposta inicial efetivamente garantiu a acessibilidade e a usabilidade para as pessoas com deficiência? Que avanços e dificuldades foram identificados pela autora da disciplina, uma professora com deficiência visual? As mudanças foram percebidas pelos/as participantes da disciplina?

Continuávamos com pesquisa que visava à acessibilidade de pessoas com deficiência visual ao AVA, mas que implicava questão mais ampla e significativa na interface dos dois processos: a inclusão escolar e a educação à distância.

Entendemos que os aspectos técnicos e culturais influenciam a compreensão sobre acessibilidade. Neste sentido, percebemos que o senso comum reduz acessibilidade à disponibilidade. É preciso compreender de modo mais amplo esse conceito e, desde a ótica da participação real e da interatividade, compreender que acessibilidade representa uma composição de características de um objeto que possibilita ao observador/ 
usuário recuperar, compreender, explorar e interagir com esse objeto no ambiente Web (Mata; Barbosa, 2007).

A World Wide Web Consortium (W3C), importante referência internacional próacessibilidade, estabelece algumas recomendações e diretrizes para a elaboração de hipertexto por parte do publicador e na leitura do conteúdo por parte dos navegadores da tecnologia assistiva, a exemplo do JAWS para Windows utilizado em nossa pesquisa. A composição desses fatores determina a acessibilidade do documento. Sobre a construção de hipertextos, são considerados fundamentais os seguintes padrões: al Disponibilizar o conteúdo em diferentes mídias, assegurando harmonia na transformação da informação; b) Estruturar o conteúdo de forma coerente e semântica. Este aspecto propicia a compreensão e a navegabilidade do documento (Mata; Barbosa, 2007).

Seguimos o estudo agregando novos conhecimentos sobre os AVA - particularmente o ambiente moodle - em relação às possibilidades do programa ledor de tela. Realizamos experiências com versões mais atuais do moodle e do JAWS, com resultados gradativamente efetivos. Os textos inseridos, inicialmente, em HTML já podem ser lidos em formato PDF, WORD E TXT, a partir da versão 7.0 do Jaws.

Como autora e professora da disciplina, neste momento, passei a ter completa autonomia para desempenhar as seguintes funções:

- Preencho campos de formulários, inclusive com anexos;

- Configuro as atividades, nomes dos campos, valor da atividade, data de abertura e fechamento;

- Posso editar os sumários, mover trechos e recursos, corrigir, deletar informações;

- Habilitar e desabilitar a mostra de semanas, sessões e atividades lo ícone desta opção é a imagem de um olho aberto ou fechado);

- Corrijo fóruns, tarefas e avalio as atividades;

Há, no entanto, dificuldades que ainda permanecem: não consigo elaborar a tabela de notas (que, aliás, é difícil para grande parte dos usuários) e não consigo inserir questionários e lições. Em 2010, além de a disciplina estar sendo parte da oferta regular do curso de Pedagogia à distância, é ofertada também como uma turma semipresencial para o curso presencial de Pedagogia. Em ambas as experiências, o conceito de acessibilidade é fortemente desenvolvido com estudantes, já no segundo semestre do curso.

Desde 2008, a disciplina semipresencial Educando, como é chamada por estudantes, foi oferecida quatro vezes. E, relacionada a essa oferta, a disciplina obrigatória que the segue, Aprendizagem e Desenvolvimento da pessoa com Necessidade Educacional 
Especial foi também ofertada como turma semipresencial, por três vezes. A disciplina ENEE é ofertada no modo semipresencial contando com apoio de quatro alunas do curso de Pedagogia que atuam como monitoras. 0 número de vagas foi ampliado para atender à demanda de estudantes das licenciaturas e outros cursos, como disciplina obrigatória ou optativa que reflete sobre temas da diversidade, das necessidades especiais, da inclusão, dos sujeitos da aprendizagem. Nossos objetivos, nessa dupla oferta das disciplinas obrigatórias da área da Educação Especial/Inclusiva, são:

- Atender um maior número de estudantes de graduação, especialmente nas licenciaturas, com formação na área de conhecimento da educação Especial/Inclusiva;

- Possibilitar o desenvolvimento de práticas pedagógicas inovadoras na área da Educação Inclusiva;

- Desenvolver material didático acessível e adequado a EaD;

- Desenvolver atividades relacionadas à educação formal e não formal que contribuam para a formação de professores e professoras do ensino básico;

- Na avaliação formal da disciplina, realizada por estudantes, tutores/as e professores/as autores/as, vários indicadores positivos podem ser destacados, tais como: al o aumento de estudantes atendidos por essa oferta, por meio da comparação entre as matrículas dos semestres consecutivos; b) a satisfação do grupo, alunos/as, tutores/as e professora, com a experiência, por meio de avaliação da disciplina; cl os índices de aprovação na disciplina, ao final da experiência; d) o desenvolvimento da prática inovadora na área da Educação Inclusiva, pelo trabalho conjunto com a tutoria e o resultado nas novas edições do curso; el o impacto positivo tanto para a formação do aluno da Pedagogia quanto para alunos de outras unidades, bem como para a formação do aluno bolsista como tutor/a de ensino a distância.

Na experiência atual, os alunos monitores são bolsistas do Programa REUNI, já que estão desenvolvendo estudos sobre a Educação Superior. As atividades listadas abaixo, relacionadas aos objetivos da disciplina, são desenvolvidas por eles e elas:

Atividade I: Acompanhamento dos alunos no desenvolvimento das atividades acadêmicas por meio da Plataforma Moodle Objetivos:

- Estimular a reflexão sobre os temas estudados com foco na compreensão da diversidade humana e nos processos de ensino aprendizagem de alunos com necessidades educacionais especiais;

- Orientar os alunos sobre a importância de recursos acessíveis em ambientes virtuais de aprendizagem; 
- Acompanhar a aplicação dos recursos de tecnologia assistiva na modalidade de educação a distância, pelos alunos matriculados na disciplina.

Atividade II: Estudo sobre recursos da tecnologia assistiva e do processo de construção de acessibilidade.

Objetivos:

- Identificar os recursos tecnológicos facilitadores da acessibilidade de alunos com necessidades especiais no processo de ensino aprendizagem.

- Acompanhar a utilização dos recursos de acessibilidade no ambiente virtual de aprendizagem pelos alunos matriculados na disciplina.

- Elaborar propostas de mediação técnica e tecnológica para os diferentes grupos de necessidades especiais;

- Apoiar os alunos na construção criativa de espaços inclusivos.

Atividade III: Análise do processo de desenvolvimento da disciplina. Objetivos:

- Realizar levantamento de dados sobre desempenho, frequência e satisfação dos alunos;

- Observar os processos particulares na construção de concepções em relação aos temas centrais da disciplina: diversidade, sujeito singular, preconceito, inclusão, exclusão, apoio.

A comparação entre a experiência pioneira com a situação atual permite verificar que o trabalho com a primeira disciplina no âmbito do Ensino de Graduação à distância colocou desafios a serem enfrentados, forçou novas respostas para novas perguntas, mobilizou estratégias criativas de todos os envolvidos, inclusive de pessoas responsáveis pela organização acadêmica institucional da experiência do Programa da UAB na Universidade de Brasília. Para além de uma mera crença inicial, no entanto, ressaltase o desenvolvimento da autonomia da professora como resultado da articulação entre o movimento complexo do sujeito que ensina e aprende com o movimento da coletividade que organizou novas formas de trabalho pedagógico colaborativo. Somente nesse cruzamento interacional, processos da tecnologia educacional podem se estabelecer como estratégias efetivas para a inclusão de pessoas com deficiência nos processos educacionais.

\section{Considerações finais}

Além das soluções viáveis ou criativas encontradas para a necessária adaptação da disciplina Educando com Necessidades Educacionais Especiais do curso de Pedagogia a Distância, tanto o processo de preparação da disciplina quanto a vivência letiva da mesma permitiram que outras disciplinas da área da Educação Inclusiva/Especial adotassem a acessibilidade em Ambientes Virtuais de Aprendizagem. 
Além disso, o desenho da disciplina trouxe a discussão sobre a acessibilidade para o âmbito de outros cursos à distância oferecidos pela instituição, pois como desdobramentos foram ministrados cursos sobre acessibilidade no Ambiente Virtual de Aprendizagem para que professores-autores/as pudessem compreender, planejar e viabilizar atendimento orientado à diversidade característica dos processos de construção da informação e do conhecimento.

Durante o processo de discussão sobre o desenvolvimento da proposta, buscamos informações sobre alunos e alunas com necessidades especiais nos diferentes cursos de graduação à distância. Até então, não havia, nos registros discentes, qualquer item que mencionasse necessidades específicas em seu processo acadêmico. A partir dessa experiência, identificamos um aluno com deficiência visual que cursava Artes. Outro resultado importante foi a proposição de experiências que levaram o conceito de espaços virtuais de aprendizagem para as disciplinas ministradas no curso de Pedagogia, na modalidade presencial e nos projetos de extensão. Os cursos "Português e Matemática com o software Braille fácil" e "Ensino de Química para alunos com deficiência visual" foram desenvolvidos com apoio do Ambiente virtual de Aprendizagem.

Além de trazer competência técnica para autores de disciplinas, capacitação de tutores a distância e, principalmente, a integração dos princípios da educação à distância à modalidade presencial por meio da acessibilidade, a experiência permitiu que os estudantes, futuros professores e professoras, integrassem ao seu perfil profissional, pela vivência prática, a concepção da acessibilidade como princípio para práticas pedagógicas. As formas específicas de construção de conhecimento com as quais temos contato durante nossa formação escolar vêm sendo impactadas pelo uso das novas tecnologias de informação. No entanto, nesse contexto, novidades tecnológicas, embora demasiadamente sedutoras, serão extremamente retrógradas se não se organizarem a partir das relações dos sujeitos envolvidos, relações que permitam a emergência de significados e sentidos subjetivos (González Rey, 2003) próprios do que seja novo ou velho.

Portanto, a articulação entre tecnologia e educação implica em reconhecer que a tecnologia em si mesma não é educativa, mas as ações dos sujeitos que a utilizam nos seus processos de ensinar e aprender é que vão permitir que ela possa vir a ser parte constitutiva de uma determinada prática educativa em que se distanciem cada vez mais concepções descritivo-reprodutivas sobre o aprender. A mesma perspectiva que confere valor ao sujeito e à sua complexidade subjetiva preside a efetividade de ações da inclusão educacional em que se utilize a tecnologia como sistema de aprendizagem.

Nossa reflexão sobre o processo indica que, em si, tanto a inclusão quanto a tecnologia não são suficientes para a transformação das concepções que presidem o modelo 
escolar tradicional. 0 potencial avanço somente será efetivado se os processos de ensino-aprendizagem forem compreendidos como atividades relacionais e se pudermos adaptar adequadamente os Ambientes Virtuais de Aprendizagem - AVA às necessidades específicas dos sujeitos envolvidos.

Concluímos indicando que, para além da satisfação com a vivência de uma experiência educacional bem sucedida, o processo permitiu, para cada um de nós envolvidos, desenvolver a tão almejada relação entre ensino e pesquisa, pois a busca de respostas aos desafios que foram se apresentando fizeram avançar nossa compreensão sobre a relação tripartite sujeitos do ensino - sujeitos da aprendizagem - conhecimento nesse contextos educacionais.

\section{Referências}

CARVALHO, Rosita Edler. Educação Inclusiva com os pingos nos "is". Porto Alegre: Mediação, 2004. CORRÊA, Juliane. Novas tecnologias da informação e da comunicação; novas estratégias de ensino/ aprendizagem. In: COSCARELLI, Carla Viana. Novas tecnologias, novos textos, novas formas de pensar. Belo Horizonte: Autêntica, 2002.

GONZÁLEZ REY, Fernando. Sujeito e Subjetividade. São Paulo: Pioneira Thomson Learning, 2003. LEVY, Pierre. A Conexão Planetária: o mercado, o ciberespaço, a consciência. São Paulo: 34, 2001. MATA, Thiago Henrique Ramos; BARBOSA Renê de Lima. Hipertexto Interativo para Usuários Deficientes Visuais (Monografia de Graduação em Computação - Licenciatura). Universidade de Brasília, 2007. Disponível em: <http://monografias.cic.unb.br/dspace/bitstream/123456789/133/1/ monografia.pdf>. Acesso em: 21 out. 2009.

MITJÁNS MARTÍNEZ, Albertina. In: ENDIPE, XIII. 2006, Recife, Anais do Encontro Nacional de Didática e Prática de Ensino. Universidade Federal de Pernambuco, abril de 2006, p.359-379.

RAPOSO, Patrícia Neves; MÓL, Gerson de Souza; PIRES, Rejane Ferreira Machado. Desenvolvimento de estratégias para o ensino de Química a alunos com deficiência visual. In: SALLES, Paulo Sérgio Bretas de Almeida; GAUCHE, Ricardo (Org.) Educação Científica, Inclusão Social e Acessibilidade. Goiânia: Cânone Editorial, 2011, p. 127-154.

RUIZ-VELAZCO, Enrique, Algunos elementos para orientar el uso y la producción de contenidos con certidun me y calidade. In: TORRES, Elizabeth Fátima; MAZZZONI, Alberto Angel, Conteúdos digitais multimídia: o foco na usabilidade e acessibilidade. Ciência da Informação, Brasília, v. 33, n. 2, p. 152-160, 2004.

TUNES, Elisabete; bartholo, ROBERTO SANTOS. 0 Trabalho Pedagógico na Escola Inclusiva. In: TACCA, MARIA CARMEN. Aprendizagem e trabalho pedagógico, Campinas: Alínea, 2006.

Recebido em fevereiro de 2011

Aprovado em julho de 2011 
Cristina Massot Madeira Coelho, doutora em Psicologia e mestre em Linguística pela Universidade de Brasília. Professora do Departamento de Teoria e Fundamentos da Faculdade de Educação da Universidade de Brasília. Publicação recente: Linguagem, Fala e Audição nos Processos de Aprendizagem: desafios e estratégias. (In: MITJÁNS MARTÍNEZ, Albertina; TACCA, Maria Carmen Villela Rosa. Possibilidades de aprendizagem: ações pedagógicas para alunos com dificuldades e deficiência. Campinas: Editora Alínea, 2011, p. 153-174). E-mail: madeiracoelhodyahoo.com.br

Patrícia Neves Raposo, mestre em Educação pela Universidade de Brasília. É professora da Secretaria de Estado de Educação do Distrito Federal e da Faculdade de Educação da Universidade de Brasília. Publicação recente: Desenvolvimento de estratégias para o ensino de Química a alunos com deficiência visual (In: SALLES, Paulo Sérgio Bretas de Almeida; GAUCHE, Ricardo (orgs.) Educação Científica, Inclusão Social e Acessibilidade. Goiânia: Cânone Editorial, 2011, p. 127-154), em co-autoria com MÓL, Gerson de Souza; PIRES, Rejane Ferreira Machado. E-mail: paneralabrturbo.com.br

Eduardo X. da Silva, odontólogo e especialista em Educação a Distância pela UnB. E-mail: exavier28agmail.com

Ana Caroline Freitas de Almeida, pedagoga e especialista em Desenvolvimento Psicológico e Inclusão Escolar pela Universidade de Brasília. Professora em turma inclusiva do $1^{\circ}$ ano do Ensino Fundamental da Secretaria de Estado de Educação do Distrito Federal. E-mail: carolfreitas_ feldyahoo.br 